\title{
Foramen magnum meningiomas: surgical treatment in a single public institution in a developing country
}

\section{Meningiomas do forame magno: tratamento cirúrgico em uma instituição pública em um país em desenvolvimento}

Benedicto Oscar Colli ${ }^{1}$, Carlos Gilberto Carlotti-Junior ${ }^{1}$, João Alberto Assirati-Junior ${ }^{1}$, Luis Alencar Biurrum Borba², Vicente de Paulo Martins Coelho-Junior' ${ }^{1}$ Luciano Neder ${ }^{3}$

\begin{abstract}
Objective: To analyze the clinical outcome of patients with foramen magnum (FM) meningiomas. Method: Thirteen patients (11 Feminine / 2 Masculine with FM meningiomas operated on through lateral suboccipital approach were studied. Clinical outcome were analyzed using survival (SC) and recurrence-free survival curves (RFSC). Results: All tumors were World Health Organization grade I. Total, subtotal and partial resections were acchieved in 69.2\%, 23.1\% and 7.7\%, respectively, and SC was better for males and RFSC for females. Tumor location, extent of resection and involvement of vertebral artery/lower cranial nerves did not influence SC and RFSC. Recurrence rate was $7.7 \%$. Operative mortality was 0 . Main complications were transient (38.5\%) and permanent (7.7\%) lower cranial nerve deficits, cerebrospinal fluid fistula (30.8\%), and transient and permanent respiratory difficulties in $7.7 \%$ each. Conclusions: FM meningiomas can be adequately treated in public hospitals in developing countries if a multidisciplinary team is available for managing postoperative lower cranial nerve deficits.
\end{abstract}

Keywords: foramen magnum meningiomas, surgical treatment, extent of resection, survival, postoperative complications.

\section{RESUMO}

Objetivo: Analisar as evoluções clínicas de 13 pacientes com meningiomas do forame magno (FM). Método: Foram estudados 13 pacientes com meningiomas do FM (11 Feminino / 2 Masculino) operados por abordagem suboccipital lateral. As evoluções clínicas foram analisadas usando curvas de sobrevida (SC) e de sobrevida livre de doença (RFSC). Resultados: Os 13 tumores eram Grau I da Organização Mundial de Saúde. Ressecções total, subtotal and parcial foram obtidas em 69,2\%, 23,1 e 7,7\%, respectivamente. A SC foi melhor para homens e a RFSC foi melhor para mulheres. Localização/ extensão da ressecção/envolvimento da artéria vertebral/nervos cranianos baixos não influenciaram a SC/RFSC. A taxa de recorrência foi 7,7\%. A mortalidade operatória foi zero. As principais complicações foram déficits de nervos cranianos baixos transitórios (38,5\%) e permanentes (7,7\%); fístula de líquido cefalorraquidiano (30,8\%) e dificuldades respiratórias transitórias e permanentes em 7,7\% cada. Conclusões: Meningiomas do FM podem ser adequadamente tratados em hospitais públicos em países em desenvolvimento se houver uma equipe multidisciplinar para cuidar de déficits de nervos cranianos baixos pós-operatórios.

Palavras-chave: meningiomas do forame magno, tratamento cirúrgico, extensão da ressecção, sobrevida, complicações pós-operatórias.

Foramen magnum (FM) meningiomas are those arising anteriorly from the inferior third of the clivus to the superior edge of the $\mathrm{C} 2$ body, laterally from the jugular tubercle to the C2 laminae, and posteriorly from the anterior border of the occipital squama to the spinal process of $\mathrm{C} 2^{1,2,3}$. Despite locating in a narrow region, they have a slow growth pattern with insidious clinical symptoms and late diagnosis ${ }^{4}$, generally after reach a considerable size. Location close to important neurovascular structures requires special skills for its surgical resection. Choice of the surgical approach, extent of bone resection, management of the vertebral artery (VA) and involvement of lower cranial nerves (CN), are the points of concern ${ }^{1,25,6,7,8,9,10,11}$.

Operative mortality for FM meningiomas has significantly decreased over the last two decades. Nevertheless, postoperative morbidity remains high and the best surgical

${ }^{1}$ Divisão de Neurocirurgia, Departamento de Cirurgia e Anatomia, Faculdade de Medicina de Ribeirão Preto, Universidade de São Paulo, Ribeirao Preto SP, Brazil; ²Universidade do Paraná, Curitiba PR, Brazil;

${ }^{3}$ Departamento de Patologia, Faculdade de Medicina de Ribeirão Preto, Universidade de São Paulo, Ribeirao Preto SP, Brazil.

Correspondence: Benedicto Oscar Colli; Departamento de Cirurgia e Anatomia, Faculdade de Medicina Ribeirão Preto; Campus Universitário USP - Bairro Monte Alegre; 14048-900 Ribeirão Preto SP, Brasil; E-mail: bocolli@fmrp.usp.br

Conflict of interest: There is no conflict of interest to declare.

Received 23 July 2013; Accepted 24 April 2014; Accepted 14 May 2014. 
approach for its resection is controversial ${ }^{3,5,11,12,13,14,15,16,17}$. This study aimed to analyze the clinical outcome of a group of patients with FM meningiomas operated in a public general hospital.

\section{METHOD}

\section{Patient population}

This study was a retrospective review of data on medical charts regarding the clinical, radiological, and surgical aspects and the outcome of 13 patients with FM meningiomas consecutively treated at our hospital from May 1995 to April 2012. They comprised $2.9 \%$ of patients with intracranial meningiomas. Four of these patients were part of previous multi-institutional publication ${ }^{14}$. Diagnosis and location of tumors were performed using computed tomography (CT) scans and/or magnetic resonance images (MRI) of the skull.

\section{Clinical findings}

Demographic characteristics of patients are presented in Table. There was a female predominance (average female/ male rate of 5.5:1). Age ranged from 28 to 77 years old (mean=54.15 standard deviation (SD) \pm 15.40 ). Follow-up ranged from 6 to 175 months (mean=47.31 \pm 37.97 ).

Signs and symptoms presented at admission are presented in Table. The most common were limbs weakness in seven (53.8\%), and occipital/neck pain and limb paresthesias in four (30.8\%) patients each. Motor signs of medullary/ upper spinal cord compression were detected in seven (53.8\%) patients, compromise of the IX, X and XI CN in four (30.8\%), of the XII in $3(23.1 \%)$, of the VI cranial nerve in two (15.4\%), and of the $\mathrm{V}$ cranial nerve in one $(7.7 \%)$ patient. Although lower $\mathrm{CN}$ deficits were present in four patients, only two of them had some related complaint.

\section{Preoperative evaluation}

Based on MRI examination, FM meningiomas were classified as anterior (attached to the anterior rim of the FM, displacing the neuroaxis posteriorly), anterolateral (located at the ventrolateral rim of the FM, displacing the neuroaxis posterolaterally), and posterolateral (located at the dorsolateral rim of the FM displacing the neuroaxis ventrolaterally) ${ }^{3}$.

\section{Surgical treatment}

Patients were operated on using microsurgical techniques. The lateral suboccipital approach with partial resection of the posterior arch of the atlas was used. Patients were operated on the three-quarter prone position and the skin incision was in S-shape starting above the mastoid process on the side of the tumor, and ending at the level of C4-C5 in the midline (Figure 1). No intraoperative cranial nerve monitoring was available for treating these patients.
In four patients with tumors placed anteriorly in the inferior clivus, the posterior third of the occipital condyle was resected after releasing the VA from the foramen transversarium of $\mathrm{C} 1$. The decision to dislocate the vertebral artery and to remove the occipital condyle and was made based on tumor type and it was cited in previous study ${ }^{14}$. For tumors with anterior implantation or implanted in the inferior clivus, the vertebral artery was displaced and the posterior third of the occipital condyle was resected.

In the postoperative period, special attention was paid to the management of patients with lower $\mathrm{CN}$ deficits by a multidisciplinary team including physicians, physiotherapists and phonoaudiologists.

\section{Clinical-radiological follow-up}

All patients were assessed clinically and the extent of resection was assessed macroscopically during surgery and postoperatively using CT or MRI during the first 72 hours, 6 months and one year after operation. Thereafter, the patients were reevaluated annually. The extent of tumor resection was defined as total (absence of residual tumor or dural enhancement), subtotal (absence of tumor but presence of dural contrast enhancement), and partial (presence of residual tumor).

Six $(46.1 \%)$ patients had the tumor attached to the anterolateral dura (Figures 1, 2), five $(38.5 \%)$ to the clival dura (anterior, Figure 3), one $(7.7 \%)$ to the posterolateral dura (Figure 4), and one (7.7\%) had a wide dural attachment (Figure 5). Tumor size and location are presented in Table. Retrospective classification according Cushing and Eisenhardt ${ }^{19}$, showed nine patients with craniospinal (69.2\% - Figures 1, 3 and 5) and four with spinocranial tumors (30.8\% - Figure 2).

\section{Outcome}

Functional outcome was assessed at the preoperative, postoperative (first 10 days), and at the last follow-up using the Karnofsky Performance Scale (KPS). Patients were classified into three groups: (1) normal function/minimal symptoms, ability to work (KPS score, 80-100); (2) independent, not working (KPS score, 70-80); and (3) moderate/severe disability (KPS score, <70). For patients who experienced tumor recurrence and clinical deterioration, the best KPS score obtained during the follow-up course was used. Follow-up analysis was performed using the Kaplan-Meier survival curve (SC), and recurrence-free survival curve (RFSC).

\section{Statistical analysis.}

Statistical analysis was performed using the Chi-square and the Fisher's exact tests to compare proportions, and the log-rank test for comparison of survival curves. An $\alpha$-error probability not exceeding $5 \%$ was considered significant for two-tailed probability tests. The tests were performed 


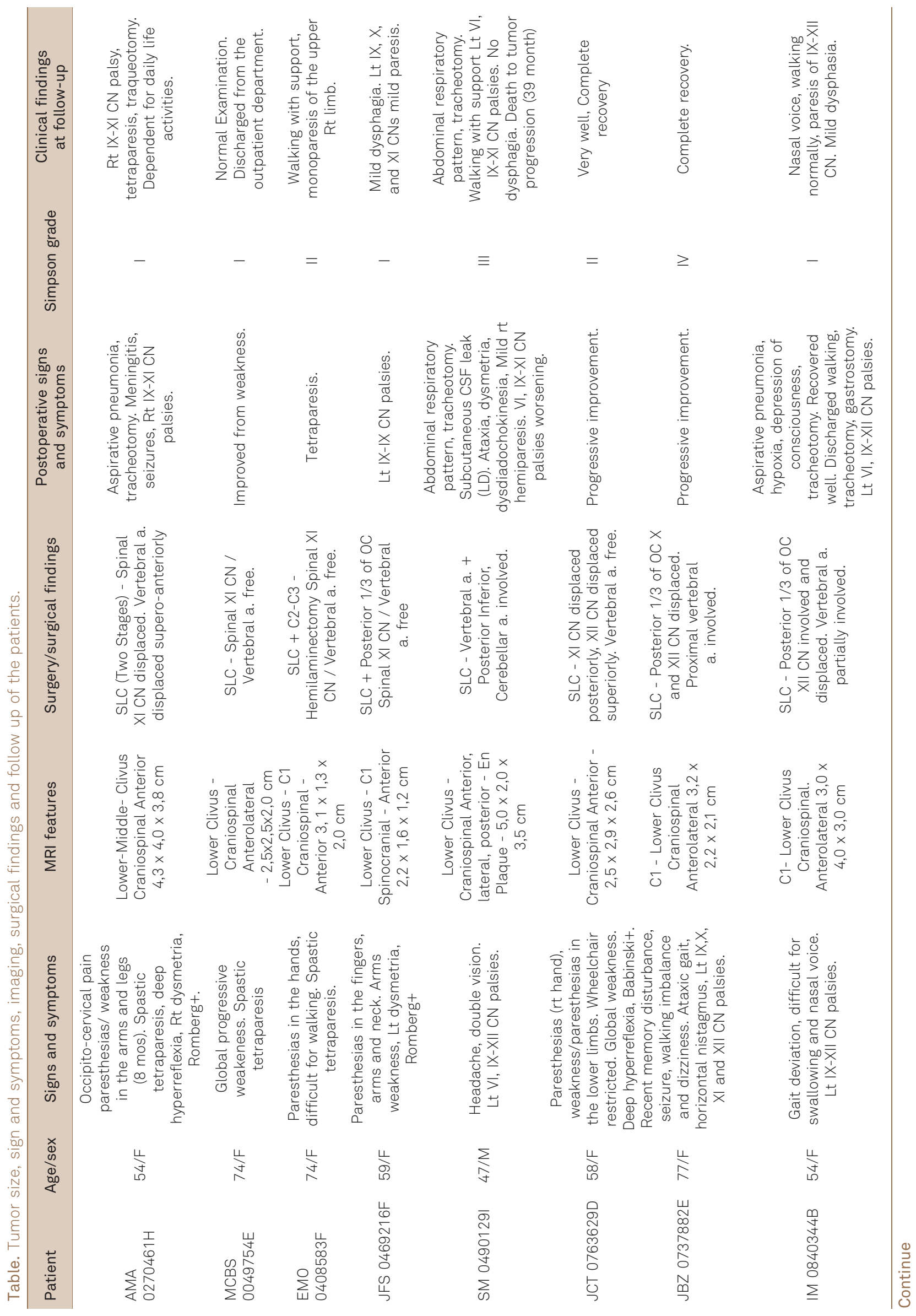




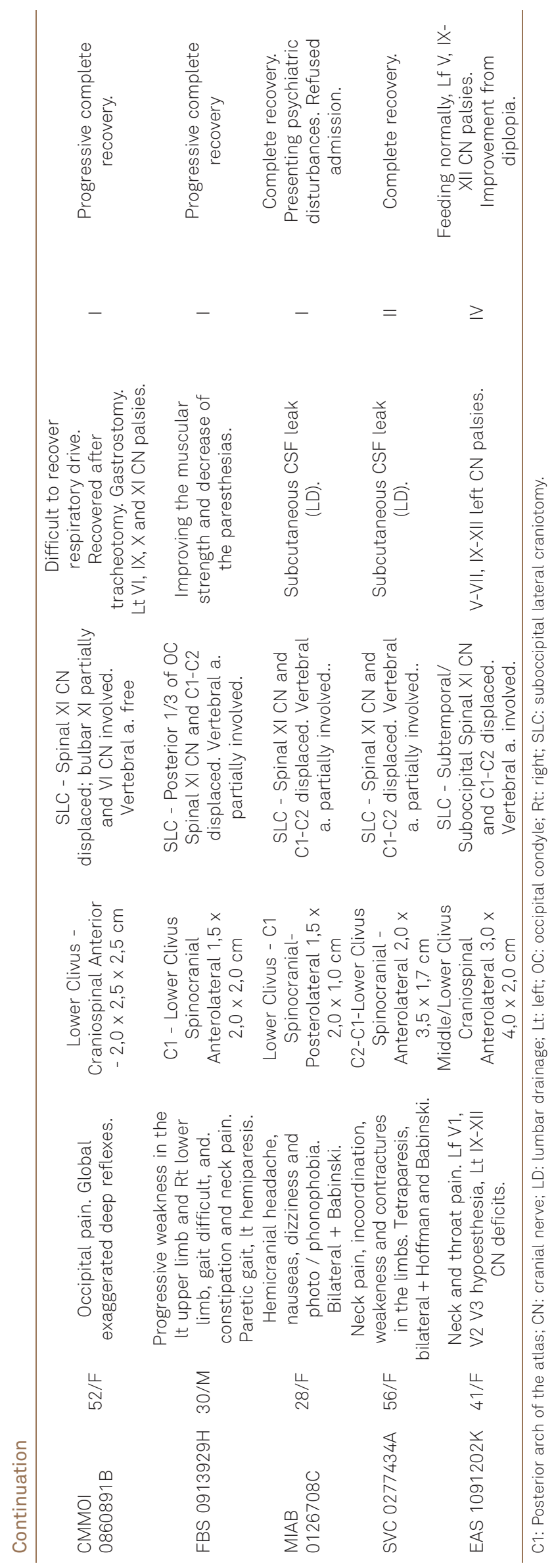

using Graph Pad PRISM (version 4.0; Graph Pad Software Inc. San Diego, CA, USA).

\section{RESULTS}

All tumors were WHO grade I meningiomas ${ }^{18}$ (five meningothelial, four transitional, one angioblastic, one fibrous, one psammomatous, and one meningioma without other specification).

\section{Follow-up review Survival}

The SC was better for male patients $(\mathrm{p}=0.0143, \mathrm{df}=1$, log-rank test). SC were similar for patients according tumor location (anterior vs. anterolateral) $(\mathrm{p}<0.5204, \mathrm{df}=1$, log-rank test), craniocaudal location (craniospinal $\nu s$. spinocranial) ( $\mathrm{p}=0.4054, \mathrm{df}=1, \log$-rank test), extent of resection (total vs. subtotal/partial) $(\mathrm{p}=0.2482, \mathrm{df}=1$, log-rank test), and involvement or not of VA/lower CN $(\mathrm{p}<0.2482$, logrank test).

\section{Recurrence-free survival}

Total recurrence rate along the follow-up was $7.8 \%$ (1 patient submitted to partial resection). The RFSC was better for female patients $(\mathrm{p}=0.0027, \mathrm{df}=1, \log$-rank test), and were similar for patients according tumor location (anterior vs. anterolateral) ( $\mathrm{p}=0.4142, \mathrm{df}=1, \log$-rank test], craniocaudal location (craniospinal vs. spinocranial) $(\mathrm{p}=0.7237, \mathrm{df}=1, \log$ rank test), extent of resection (total vs. subtotal/partial) ( $p=0.1573, d f=1$, log-rank test), and involvement of the VA and and/or lower $\mathrm{CN}(\mathrm{p}<0.2207$, log-rank test)

\section{Clinical-radiological outcome}

Total resection was achieved in 9 (69.2\%), subtotal in three $(23.1 \%)$, and partial resection was achieved in one $(7.7 \%)$ patient. Subtotal removal was achieved in three patients with anterolateral meningiomas with large dural attachment and involvement of the VA/lower CN. Partial resection (decompression of the medulla and upper spinal cord) was obtained in a patient with an "en plaque" meningioma attached anteriorly and extending laterally and posteriorly, involving the lower CN (Figure 5). This patient died 39 months later due to tumor progression.

The main preoperative signs and symptoms improved in nine (69.2\%), 1 (7.7\%) remained unchanged and three patients had some worsening (Table). Occipital/neck pain disappeared in all four patients, and paresthesias improved in three (75\%) of four patients. Motor signs of medullary/ upper spinal cord compression marked improved or disappeared in $6(85.7 \%)$ of 7 patients.

Two patients with preoperative VI CN deficits did not improve. The four patients with preoperative IX and X CN 

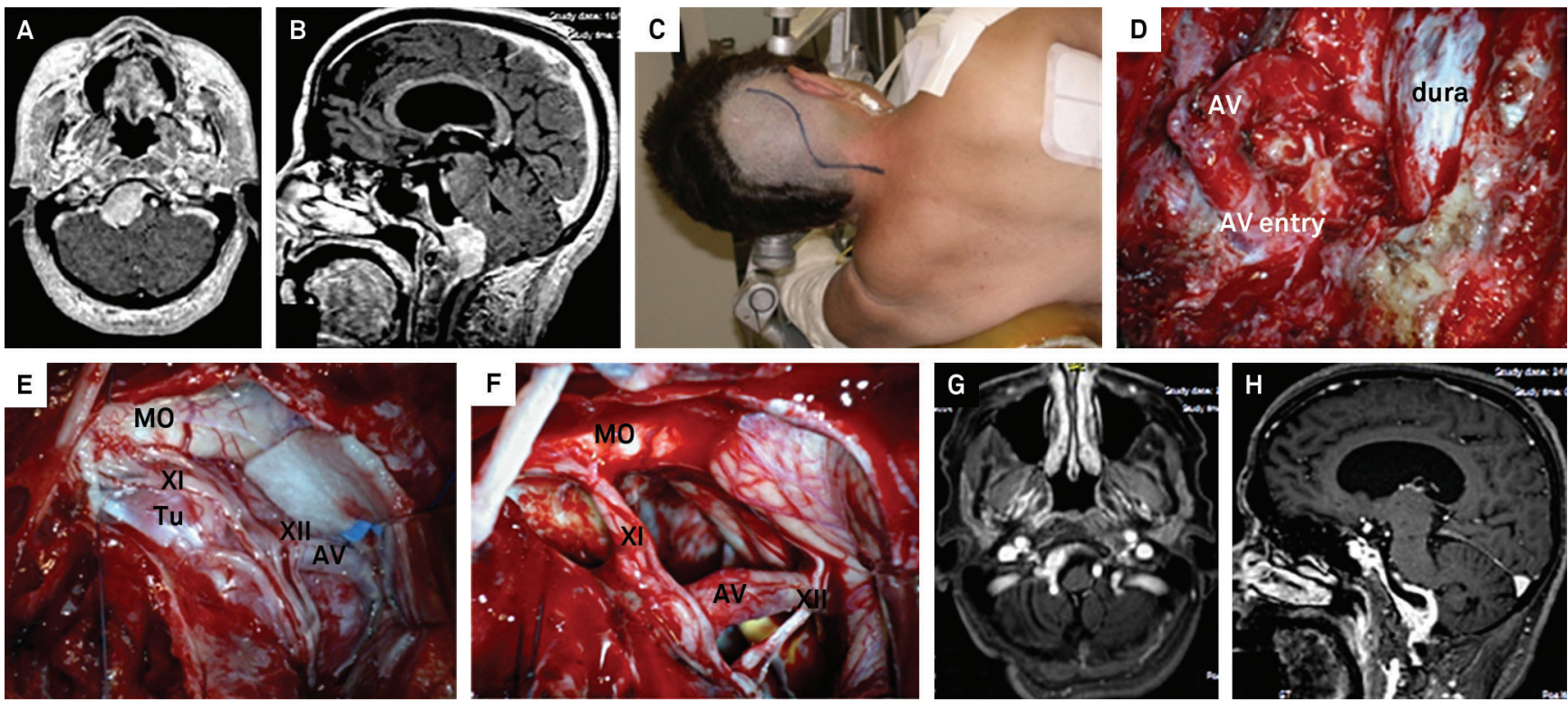

Figure 1. Pre- $(A, B)$ and postoperative $(G, H)$ resonance magnetic images with gadolinium and operative findings of a 70 -year-old female with recent memory disturbance, seizures, walking imbalance and dizziness and ataxic gait, horizontal nistagmus, left IX,X, $\mathrm{XI}$ and XII cranial nerve (CN) palsies at examination. A-B. T1-weighted images showing an anterolateral craniospinal tumor in the foramen magnum, displacing the medulla posterolaterally. C. Incision used for suboccipital lateral approach to the tumor. Exposure of the dura-mater of the posterior fossa after craniotomy and of the entry point of the vertebral artery (VA) in dura. E. exposure of the tumor (tu) displacing the medulla (MO), the VA into the posterior fossa behind the tumor, and the XI and XII CN displaced posteriorly, over the tumor. F. VA, XI and XII CN and medulla after tumor resection. G-H. Four years postoperative T1weighted images showing unchanged residual tumor in the right anterolateral dura-mater.

deficits showed great functional improvement at the last neurological examination. One (25\%) patient with preoperative XI cranial nerve deficit had complete recovery and another (25\%) have partial improvement. Partial improvement of XII cranial nerve deficit was detected at the last follow-up in one (33.3\%) of 3 patients with preoperative deficit.

\section{Postoperative outcome}

Preoperative, immediate postoperative and follow-up KPS scores were $\geq 80$ in 9 (69.2\%), 5 (38.5\%), and 10 (76.9\%) respectively (no significant difference, $\mathrm{p}=0.1028$, Chi-square test, $\mathrm{df}=2$ ). Preoperative and immediate postoperative KPS scores $\geq 80$ were similar $(\mathrm{p}=0.2377$, Fisher exact test, $\mathrm{df}=1$ ) and KPS scores $\geq 80$ assessed at the last follow up was better than those assessed in the immediate postoperative $(\mathrm{p}=0.0414$, Fisher exact test, $\mathrm{df}=1)$. Four (30.8\%) patients experienced immediate postoperative deterioration, two transients (KPS scores $=70$ ), and two permanents (KPS scores=60), 7 (13.4\%) had their KPS scores unchanged and only one experienced improvement $(\mathrm{KPS}=70)$. Assessment at the last follow-up demonstrated 8 (61.5\%) additional patients presenting improvement from the previous evaluation, 4 (30.8\%) kept the same KPS score and one had a KPS score worse than the preoperative.

Four $(44.4 \%)$ patients with craniospinal (3 transients and one permanent), and one (25\%) with spinocranial (transient) experienced immediate postoperative deterioration, four (44.4\%) with craniospinal and $3(75.0 \%)$ with spinocranial
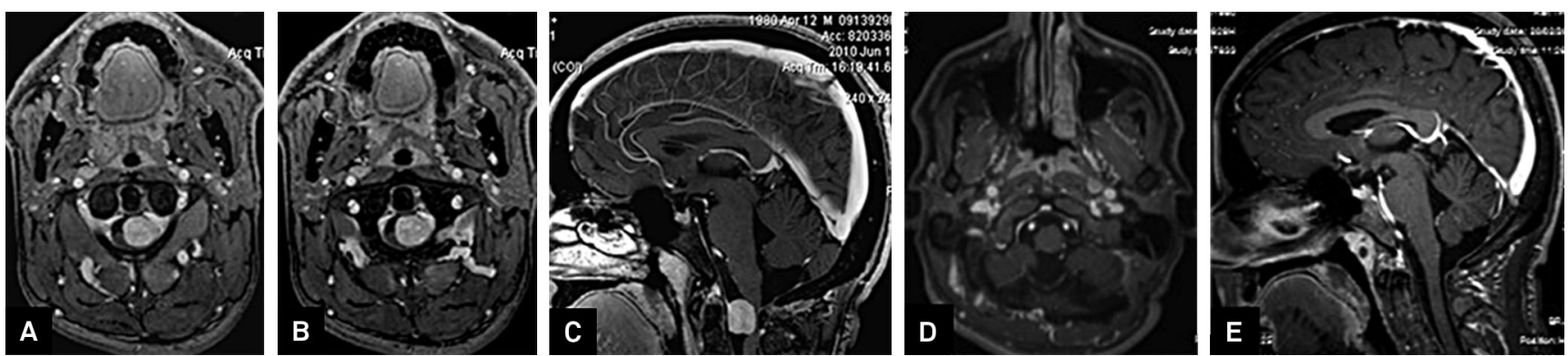

Figure 2. Resonance magnetic images with gadolinium of a 30-years-old male with progressive weakness in the left upper limb and right lower limb, gait difficult, and. constipation and neck pain and paretic gait, and left hemiparesis at examination. A-C. Preoperative T1-weighted images showing an anterolateral spinocranial tumor in the foramen magnum, displacing the medulla and the upper cord posterolaterally. D-E. Eight months postoperative T1-weighted images showing no residual tumor. 

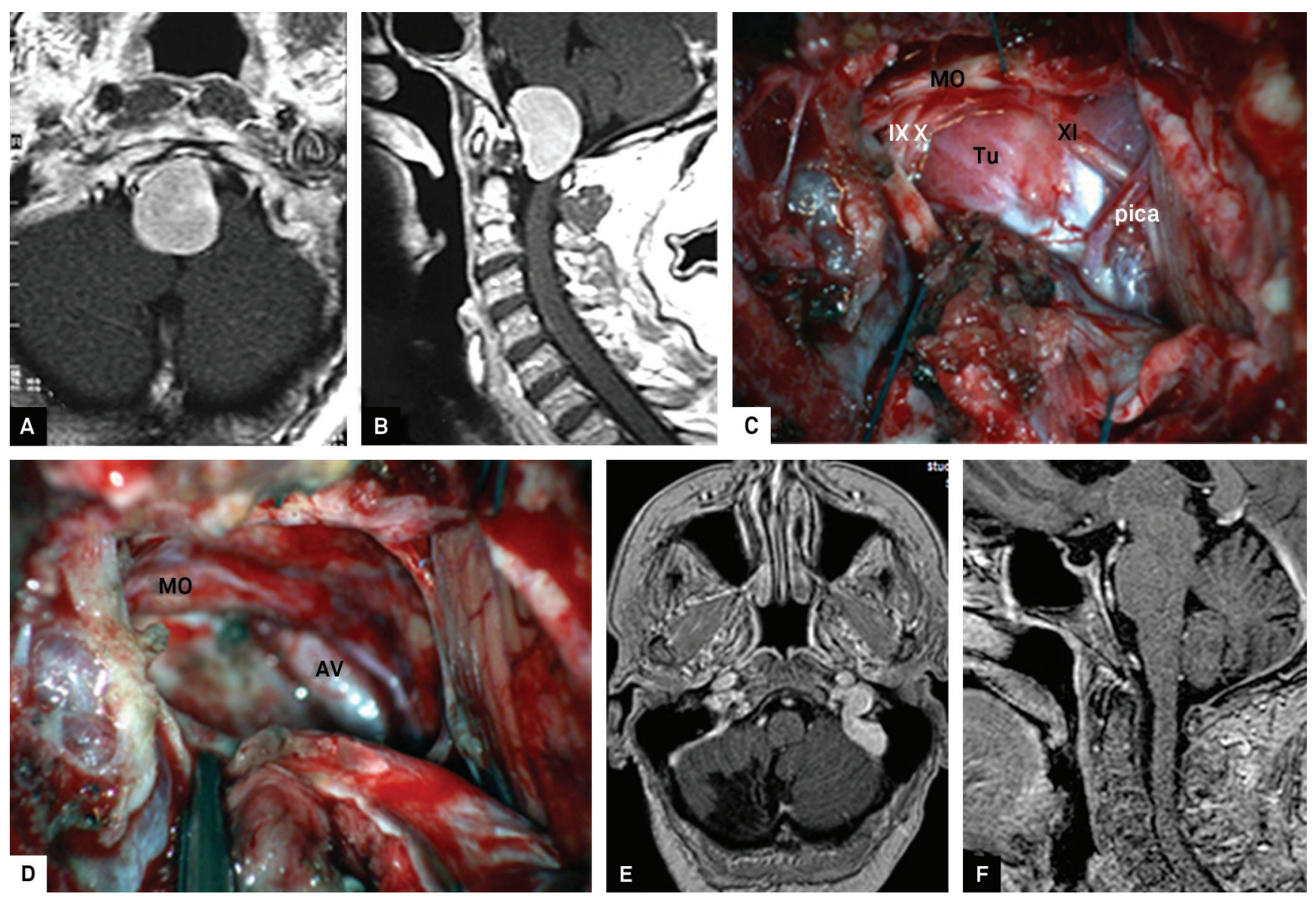

Figure 3. Pre- $(A, B)$ and postoperative $(G, H)$ resonance magnetic images with gadolinium and operative findings of a 58-year-old female with paresthesias on the right hand, weakness/paresthesias in the lower limbs. Wheelchair restricted, global weakness, deep hyperreflexia, Babinski +. A-B. Preoperative T1-weighted images showing an anterior craniospinal tumor in the foramen magnum, displacing the medulla posteriorly. C-D. exposure of the tumor (tu) displacing the medulla (MO), the posterior inferior cerebellar artery (PICA) and the IX and X and XI cranial nerve (CN), and VA, and medulla after tumor resection. F-G. Ninety months postoperative T1-weighted images showing no residual tumor.

tumors had their KPS scores unchanged and one (11.1\%) with craniospinal tumor experienced improvement in his KPS score at the immediate postoperative evaluation. Assessment at the last follow-up demonstrated four
(44.4\%) additional patients with craniospinal and three (75.0\%) with spinocranial tumors presenting improvement from the previous evaluations, 4 (44.4\%) with craniospinal and one with spinocranial tumors kept the same KPS score
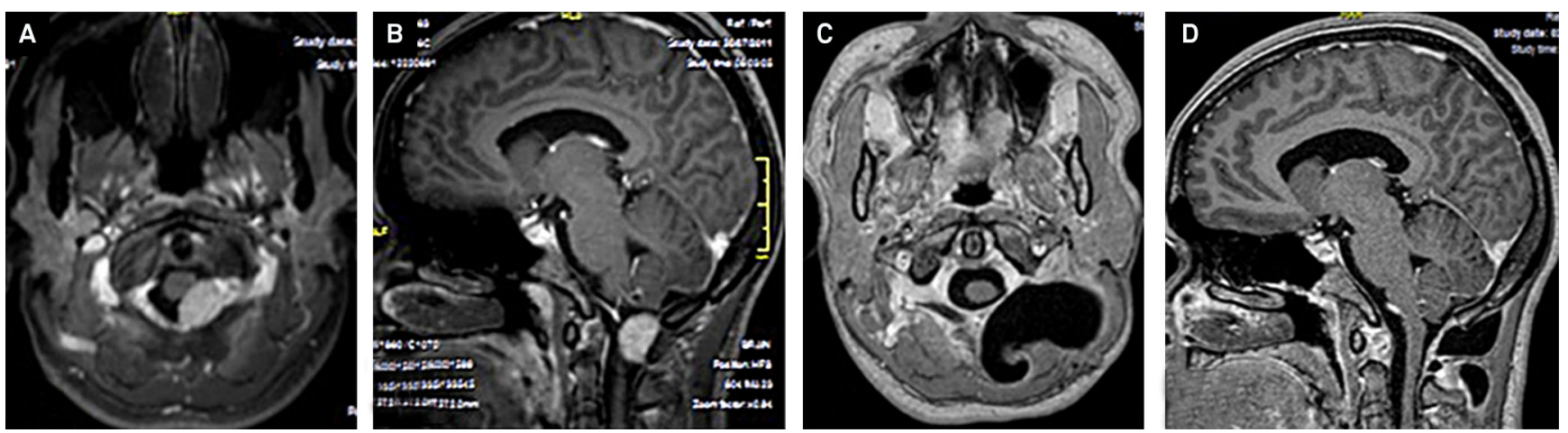

Figure 4. Resonance magnetic images with gadolinium of a 28-years-old female with hemicranial headache, nauseas, dizziness and photo / phonophobia and bilateral + Babinski at examination. A-B. Preoperative T1-weighted images showing a posterolateral craniospinal tumor in the foramen magnum, displacing the medulla and the upper cord anterolaterally. C-D. Five months postoperative T1-weighted images showing no residual tumor and a residual fluid collection in the subcutaneous layers originated from a cerebrospinal fluid fistula. 

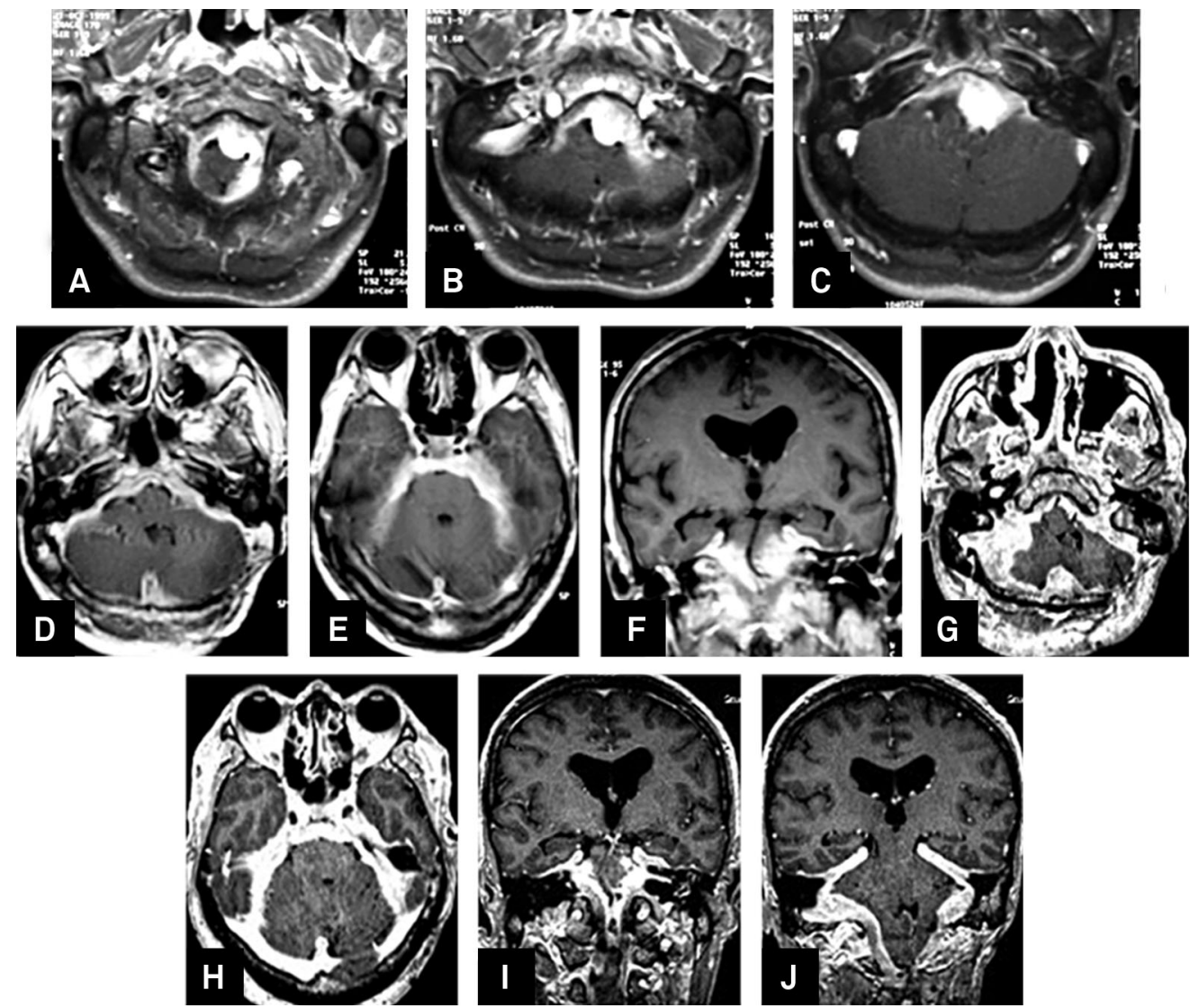

Figure 5. Resonance magnetic images with gadolinium of a 47-years-old male with headache and double vision and with left VI, IX-XII cranial nerve (CN) palsies at examination. A-C. Preoperative T1-weighted images showing an anteroposterolateral tumor in the foramen magnum extending to the opposite side. displacing the medulla and the upper cord posterolaterally. D-F. 10 months after partial resection T1- weighted images showing an en plaque spreading of the tumor through the dura mater. G-J. 3 years after the partial resection T1- weighted images showing an en plaque spreading of the tumor through the dura mater, including invasion of $\mathrm{CN}$ of foramina.

and one patient with craniospinal tumors had a KPS score worse than the preoperative and immediate postoperative KPS scores. The number of patients with craniospinal and with spinocranial tumors with $\mathrm{KPS} \geq 80$ in the pre-, postoperative and the last follow-up assessment were similar $(\mathrm{p}=0.5884$, Chi-square test, $\mathrm{df}=2)$

\section{Mortality and morbidity}

There was no operative mortality. One patient died due to tumor progression and another due to other cause (39 and 72 months, respectively, after surgery).

Six $(46.2 \%)$ patients had postoperative neurological deficits (Table), five of them transient (38.5\%), and one (7.7\%) permanent. New lower CN deficits were observed in three patients, two of them with concomitant transient VI cranial nerve palsy, one with cerebellar signs and another with meningitis and seizures. One patient had new transient VI and VII nerves paresis. Two patients had transient worsening of a previous motor deficit (one hemiparesis and one tetraparesis).

One patient with postoperative VI CN deficit had partial improvement and another had complete recovery. There was great functional improvement of the IX and $\mathrm{X} \mathrm{CN}$ postoperative deficits in two $(66.7 \%)$ of three patients at the last follow-up, despite persistence of paresis of these nerves at neurological examination. Only one of seven (4 with preoperative and three with postoperative) patients with IX and X CN paresis persisted with severe dysphagia needing enteral feeding. One (33\%) patient with postoperative XI CN deficit had complete recovery and another (33.3\%) have partial improvement.

Three $(23.1 \%)$ patients had subcutaneous craniospinal fluid fistula causing bulging of the operative wound. They were treated with lumbar drainage. Two (15.4\%) patients had respiratory difficulties due to cervico-medullary disturbance and needed tracheotomy (one transient and another permanent).

\section{DISCUSSION}

FM meningiomas are rare tumors (1.5-3.2\% of intracranial meningiomas $)^{3,5}$. They comprised $2.9 \%$ of patients with histopathological diagnosis of intracranial meningioma operated at our hospital. 


\section{Classification}

Bogorodinsky, in 1936, introduced the name craniospinal for meningiomas originating from the basilar groove projecting through the FM and Cushing and Eisenhardt, in 1938, named as spinocranial those originated lateral or posterolateral to the upper spinal cord, projecting into the $\mathrm{FM}^{19}$.

More recently a classification based on the dural insertion of these meningiomas in the axial plane $e^{2,3}$ has been considered more useful from the surgical point of view ${ }^{13}$. The tumors are classified according to: (1) the compartment of development (intradural, extradural, and intra- and extradural), (2) the insertion on the dura in the axial plane (anterior: insertion on both sides of the anterior midline; lateral: insertion between the midline and the dentate ligament; and posterior: insertion posterior to the dentate ligament), and (3) the relation to the VA (above the VA, below the VA, and on both sides of the VA). FM meningiomas have anterolateral attachment in 52-84\%, anterior in $4-45 \%$, posterolateral in $2.5-20 \%$, and posterior in $5-7 \%^{1,2,6,7,13,20}$. The distribution in our series was similar, with no case of posterior attachment. One of our cases had an en plaque meningioma attached to the anterior, lateral, and posterior dura-mater and, after a partial resection it spread to the dura of the posterior fossa, including the $\mathrm{CN}$ outlet foramina and the tentorium (Figure 5). These type of tumor is considered rare re, $^{2,13}$.

\section{Surgical treatment \\ Surgical approach}

Posterior FM meningiomas can safely be resected via a midline suboccipital approach ${ }^{3,13}$. Nevertheless, the best approach for lateral and for anterior FM meningiomas is controversial ${ }^{2,3,9,14,15,16,17,21,22,23}$. Midline approach is used mainly for selected large tumors that can be debulked allowing space for dissection of the surround neurovascular structures. Three basic approaches has been used for this proposal: the transoral, the far-lateral, posterolateral or lateral suboccipital and the extreme-lateral or anterolateral ${ }^{3}$. The transoral approach ${ }^{24}$, sporadically used, did not acquired great acceptance specially because of its increased risk of cerebrospinal fluid leak and meningitis, difficult access for tumors with lateral extension and risk of postoperative craniocervical instability and velopalatine insufficiency ${ }^{24}$. The far-lateral and the extreme-lateral approaches are the most utilized nowadays ${ }^{3}$. In both approaches it is possible to remove partially the occipital condyle but they provide different exposure because of different angles of approaches to the anterior $\mathrm{FM}^{3}$. The extreme-lateral approach requires VA transposition for drilling the occipital condyle ${ }^{5,7,10}$.

Extent of removal of the occipital condyle has been perfomed according the contralateral extension of the tumor ${ }^{3}$, ranging from $0-66 \%^{3,7,9,17,25}$. Bassiouni et al. ${ }^{13}$, divided the far-lateral approach in transcondylar and retrocondylar if the occipital condyle is drilled or not. They found five published series using the retrocondylar approach, with $100 \%$ of complete resection in three of them ${ }^{7,825}$, and 90 and $96 \%$ in the two others ${ }^{13,15}$, with good results and low rates of surgical morbidity and mortality. In our series, the farlateral approach was used for all patients and removal of the posterior third of the occipital condyle after VA transposition was performed in four of them (three with anterolateral tumors and one with a posterolateral tumor). In a retrospective analysis, one of these patients could have its tumor resected without occipital condyle resection. Although some authors consider occipital condyle removal and mobilization of the VA be crucial for anterior and anterolateral FM meningiomas resection ${ }^{10}$, we agree with others that the far-lateral approach is enough for this purpose $^{3,7,8,9,12,13,14,17,25,26}$, and that, generally, there is no need of VA transposition for intradural tumors ${ }^{3}$. In our opinion, occipital condyle should be tailored for specific cases, generally for small anterior placed tumors extending to the opposite side.

\section{Extent of tumoral resection}

Complete, subtotal, and partial resections were reported in 77,16 , and $7 \%$, respectively, in a multicentric study ${ }^{27}$, and most recent series reported predominantly complete or subtotal removal of the tumor and, exceptionally, partial removal ${ }^{2,7,8,9,10,11,12,13,15,16,17,20,21,22,23,24,25,27,28,29,30}$. Factors preventing complete resection are tumor adherences to CN/VA and invasiveness of the tumor ${ }^{3,9,27}$. Complete removal is higher during the first surgery than after recurrence ${ }^{5}$. Leaving small residual tumor can reduce morbidity in recurrent tumors ${ }^{2,13}$, but radical removal allows long stable postoperative course, despite transient morbidity due to lower $\mathrm{CN}$ deficits ${ }^{5}$. Our results are in agreement with the recent literature (complete removal in $69.2 \%$, and subtotal in $23.1 \%$ ). Subtotal resections were due to extensive anterior dural attachment and involvement of the VA/lower $\mathrm{CN}$ deficits.

\section{Outcome and prognosis}

Factors influencing the prognosis of patients with FM meningiomas are anterior location ${ }^{2,9}$, tumor size (bigger lesions are easier to be resected), tumor invasiveness, extradural extension ${ }^{2,3}$, VA encasement ${ }^{11,20}$, absence of arachnoidal layer ${ }^{13,28}$, and adherences in recurrent lesions ${ }^{9,10,13}$. Although our small number of patients do not allow incisive affirmatives, despite of tumor involvement of VA/lower CN in some of our patients, we did not find these variables to be prognostic factors.

Although the SC have been better for male patients and the RFSC for female patients, the small number of patients do not allow definitive conclusions about differences in prognosis between both sexes for patients with FM meningiomas.

Not as expected, the SC and RFSC were similar for patients submitted to total and to subtotal resection. 
However, only one among our patients recurred (patient submitted to partial resection), and nine with total resection, and three with subtotal resection (one with 6-months, one with 22-months and one with 5-years follow-up). did not recur. Therefore we believe that these results should be attributed to the small number and to the short follow-up of patients with subtotal resection.

Improvement from preoperative signs and symptoms occurs in $57-100 \%$, patients with FM meningiomas after surgery, $2.5-20 \%$ remain unchanged and deterioration is observed in 7.5-17.4\% $\%^{2,5,11,13,15,16,17,21,22,25,26}$. Sixty percent of the patients with neurological deficits have complete recovery or had good improvement. Despite a immediate postoperative deterioration, there was a tendency of increase (not significant) in the percentage of our patients with good outcome (KPS $\geq 80$ ), from preoperatively to the last assessments.

\section{Morbidity and mortality}

Morbidity after resection of FM meningiomas includes lower $\mathrm{CN}$ deficits, hemiparesis, tetraparesis, sensory deficits, hydrocephalus, craniospinal fluid leak, meningitis and general complications as pneumonia, and respiratory failure. In the last two decades transient and permanent morbidity ranged from $0-72.5 \%^{5,9,11,13,14,15,16,17,21,22,24,29}$ and from 0-30\% $\%^{2,5,11,12,13,15,16,17,21,22,23,25,26,29,30}$, respectively. Permanent morbidity is directed related to the location and extent of the tumor. Postoperative complications occurred in $(69.2 \%$ of the patients in our series, $46.8 \%$ with neurological deficits
(83.3\% transient). Preoperative lower CN deficits are associated with better prognosis then new deficits due to previous adaptation to the dysfunction. New deficits may be catastrophic if not addressed intensively ${ }^{7,8}$. Our ability to manage these patients had considerable improvement since some years ago when a multidisciplinary team becomes available at our hospital. Despite lower CN palsy detected at neurological examination in the follow-up, three of five patients with preoperative and two of three with postoperative deficits acquired normal function of swallowing, indicating that even new cranial nerve dysfunction can be compensated, allowing good quality of life. Subcutaneous fistula was other frequent requiring transient lumbar drainage.

Overall mortality for FM meningiomas resection decreased from approximately $13 \%$ (up to $45 \%$ ) to $6.2 \%$ (0-25\%) over the last 20 years with rates above $10 \%$ mainly observed in small series ${ }^{3}$. We observed no operative mortality and the overall mortality was $15.3 \%$.

In conclusion, surgical resection of FM meningiomas remains a challenge due to considerable mortality and morbidity rates. Extensive skull base approach may be helpful but is not essential; management of these tumors should be tailored for each patient, based on preoperative images for achieving the best way to remove the tumor. Our results demonstrated that these tumors can be treated in a general public hospital in developing countries with results comparable to the literature, if a multidisciplinary team is available for managing postoperative lower $\mathrm{CN}$ deficits.

\section{References}

1. George B. Meningiomas of the foramen magnum. In: Schmidek $\mathrm{HH}$ (Ed.). Meningiomas and Their Surgical Management. Philadelphia: Saunders (W.B.) Company Ltda; 1991:459-470.

2. George B, Lot G, Boissonnet H. Meningioma of the foramen magnum: a series of 40 cases. Surg Neurol 1997;47:371-379.

3. Bruneau M, George B. Foramen magnum meningiomas: detailed surgical approaches and technical aspects at Lariboisiere Hospital and review of the literature. Neurosurg Rev 2008;31:19-33.

4. Menezes AH, Traynelis VC, Fenoy AJ, Gantz BJ, Kralik SF, Donovan KA. Honored guest presentation: surgery at the crossroads: craniocervical neoplasms. Clin Neurosurgery 2005;52:218-228.

5. Arnautovic KI, Al-Mefty O, Husain M. Ventral foramen magnum meningiomas. J Neurosurg 2000;92(Suppl 1):S71-S80.

6. Bertalanffy $\mathrm{H}$, Seeger W. The dorsolateral, suboccipital, transcondylar approach to the lower clivus and anterior portion of the craniocervical junction. Neurosurgery 1991;29:815-821.

7. Kratimenos GP, Crockard HA. The far lateral approach for ventrally placed foramen magnum and upper cervical spine tumours. $\mathrm{Br} J$ Neurosurg 1993;7:129-140.

8. Margalit NS, Lesser JB, Singer M, Sen C. Lateral approach to anterolateral tumors at the foramen magnum: factors determining surgical procedure. Neurosurgery 2005;56(Suppl 2):S324-S336.

9. Samii M, Klekamp J, Carvalho G. Surgical results for meningiomas of the craniocervical junction. Neurosurgery 1996;39:1086-1095.
10. Sen CN, Sekhar LN. An extreme lateral approach to intradural lesions of the cervical spine and foramen magnum. Neurosurgery 1990;27:197-204.

11. Wu Z, Hao S, Zhang J, et al. Foramen magnum meningiomas: experiences in 114 patients at a single institute over 15 years. Surg Neurol 2009;72:376-382.

12. Bertalanffy H, Gilsbach JM, Mayfrank L, Klein HM, Kawase T, Seeger W. Microsurgical management of ventral and ventrolateral foramen magnum meningiomas. Acta Neurochir 1996;65(Suppl):S82-S85.

13. Bassiouni H, Ntoukas V, Asgari S, Sandalcioglu El, Stolke D, Seifert $\checkmark$. Foramen magnum meningiomas: clinical outcome after microsurgical resection via a posterolateral suboccipital retrocondylar approach. Neurosurgery 2006;59:1177-1187.

14. Borba LA, de Oliveira JG, Giudicissi-Filho M, Colli BO. Surgical management of foramen magnum meningiomas. Neurosurg Rev 2009;32:49-60.

15. Boulton MR, Cusimano MD. Foramen magnum meningiomas: concepts, classifications, and nuances. Neurosurg Focus 2003;14:10.

16. Kano T, Kawase T, Horiguchi T, Yoshida K. Meningiomas of the ventral foramen magnum and lower clivus: factors influencing surgical morbidity, the extent of tumour resection, and tumour recurrence. Acta Neurochir (Wien);152:79-86.

17. Pamir MN, Kilic T, Ozduman K, Ture U. Experience of a single institution treating foramen magnum meningiomas. J Clin Neurosci 2004;11:863-867. 
18. Kleihues P CWe. World Health Organization Classification of Tumours. Pathology and genetics of tumors of the nervous system. Lion: IARC; 2000.

19. Cushing $H$, Eisenhardt L. Meningiomas of the cerebellar chamber. Tumors of the basilar groove. In: Cushing $\mathrm{H}$, Eisenhardt $\mathrm{L}$ (Eds.). Meningiomas. Their classification, regional behavior, life history, and surgical end results. Springfield: Charles C Thomas 1938:169-198.

20. Guidetti B, Spallone A. Benign extramedullary tumors of the foramen magnum. Adv Tech Stand Neurosurg 1988;16:83-120.

21. Gupta SK, Khosla VK, Chhabra R, Mukherjee KK. Posterior midline approach for large anterior/anterolateral foramen magnum tumours. Br J Neurosurg 2004;18:164-167.

22. Kandenwein JA, Richter HP, Antoniadis G. Foramen magnum meningiomas-experience with the posterior suboccipital approach. Br J Neurosurg 2009;23:33-39.

23. Talacchi A, Biroli A, Soda C, Masotto B, Bricolo A. Surgical management of ventral and ventrolateral foramen magnum meningiomas: report on a 64-case series and review of the literature. Neurosurg Rev 2012;35:359-368.

24. Crockard HA, Sen CN. The transoral approach for the management of intradural lesions at the craniovertebral junction: review of 7 cases. Neurosurgery 1991;28:88-98.
25. Nanda A, Vincent DA, Vannemreddy PS, Baskaya MK, Chanda A. Farlateral approach to intradural lesions of the foramen magnum without resection of the occipital condyle. J Neurosurg 2002;96:302-309.

26. Goel A, Desai K, Muzumdar D. Surgery on anterior foramen magnum meningiomas using a conventional posterior suboccipital approach: a report on an experience with 17 cases. Neurosurgery 2001;49:102-107.

27. George B, Lot G, Velut S, Gelbert F, Mourier KL. [French language Society of Neurosurgery. 44th Annual Congress. Brussels, 8-12 June 1993. Tumors of the foramen magnum]. Neurochirurgie 1993;39 Suppl 1:1-89.

28. George B, Dematons C, Cophignon J. Lateral approach to the anterior portion of the foramen magnum. Application to surgical removal of 14 benign tumors: technical note. Surg Neurol 1988;29:484-490.

29. Marin Sanabria EA, Ehara K, Tamaki N. Surgical experience with skull base approaches for foramen magnum meningioma. Neurol Med Chir (Tokyo) 2002;42:472-480.

30. Pirotte BJ, Brotchi J, DeWitte O. Management of anterolateral foramen magnum meningiomas: surgical vs. conservative decision making. Neurosurgery 2010;67(Suppl Operative 3):S58-S70. 